Revista Destaques Acadêmicos, Lajeado, v. 9, n. 3, 2017. ISSN 2176-3070 DOI: http://dx.doi.org/10.22410/issn.2176-3070.v9i3a2017.1460 www.univates.br/revistas

\title{
PNEUMONIA LIPOÍDICA E A IMPORTÂNCIA DA HISTÓRIA CLÍNICA PARA O DIAGNÓSTICO DIFERENCIAL: RELATO DE CASO
}

\author{
Bruna Zagonel $^{1}$, João Henrique Ardenghi Feldens², Dennis Baroni Cruz ${ }^{3}$
}

Resumo: A pneumonia lipoídica é decorrente da aspiração de óleo mineral, de óleos vegetais e animais presentes nos alimentos ou nos medicamentos e pode resultar em pneumonia lipoide (lipoídica). A causa mais comum é o uso de óleo mineral para tratamento da constipação. O padrão encontrado nos exames de imagem pode sugerir muitas doenças sendo a história clínica de extrema importância para um diagnóstico final e tratamento adequado. O presente estudo tem como objetivo descrever via relato de caso, os achados radiológicos e a importância da história clínica para o diagnóstico diferencial. Como procedimentos metodológicos utiliza a coleta de dados via consulta de banco de imagens e entrevista com paciente do estilo anamnese.

Palavras-chave: Pneumonia Aspirativa. Diagnóstico Diferencial. Pneumonia Exógena.

\section{INTRODUÇÃO}

A pneumonia lipoídica é causada pelo uso de óleo mineral para tratamento da constipação usada tanto por adultos como por crianças. As manifestações encontradas nos exames de imagem irão depender da quantidade de material aspirado e se o processo é agudo ou crônico (MULLER et al., 2005). São observados desde pacientes assintomáticos, a quadros graves, que ameaçam a vida (HARO et al., 1998).

O diagnóstico da pneumonia lipoídica exógena é baseado na história de exposição a algum tipo de óleo, juntamente com a radiografia de tórax e tomografia computadorizada (TC) e na presença de macrófagos com corpos de

1 Acadêmica de Medicina, Univates, Lajeado/RS.

2 Médico, Docente do Curso de Medicina da Univates, Lajeado/RS, Residência Médica em Radiologia e Diagnóstico por Imagem pelo Hospital de Clínicas de Porto Alegre.

3 Médico Doutor, Docente do Curso de Medicina da Univates, Lajeado/RS, Especialista em Patologia. 
gordura no escarro ou no lavado bronco alveolar (MARCHIORI et al., 2007). Os achados encontrados nos exames de imagem podem ser compatíveis com diversas outras patologias, por isso, convém indagar sobre uso de substâncias que podem não ter sido referidas pelo paciente durante a consulta, sendo essencial uma história clínica completa para ajudar a elucidar o diagnóstico, ressaltando que nem sempre essa etiologia é lembrada.

Assim, este artigo tem o objetivo de relatar o caso de um paciente com pneumonia lipoídica, tendo como diferencial a história clínica que associada aos exames de imagem e com o histórico do paciente de fatores de risco para aspiração foram essenciais para o diagnóstico correto da pneumonia de etiologia lipídica.

\section{RELATO DE CASO}

Paciente masculino, branco, 65 anos, empresário, casado, procedente e residente em Lajeado, Rio Grande do Sul, Brasil, foi diagnosticado com pneumonia lipoídica em setembro de 2015, por uso crônico de óleo mineral.

Aos 60 anos teve agravo da constipação que se iniciara alguns anos antes, por conta própria o mesmo iniciou o uso de óleo mineral, usando de 2 a 4 frascos diariamente antes de dormir. Seguiu por dois anos com essa ingesta, caso ficasse sem usar o óleo mineral por um dia sentia dores e desconforto abdominal não conseguindo evacuar.

Paciente então com 62 anos, realizou uma viagem de férias onde teve episódio de dispneia grave, tosse, dor abdominal, cansaço e fraqueza severa antecipando a sua volta. Encaminhou-se para Clínica Particular em Estrela, Rio Grande do Sul, onde realizou tomografia de alta resolução evidenciando área com opacidade em vidro fosco em lobo médio e lobo inferior do pulmão direito (FIGURA 1).

Em seguida, foi ao pneumologista que, após consulta, com minuciosa anamnese e exame físico além dos exames de imagem o diagnóstico de Pneumonia Lipoídica foi suspeitado pelo histórico do paciente de usar o óleo mineral diariamente antes de dormir, com o agravante de o paciente sempre dormir virado para o lado direito, segundo ele aliviava o desconforto abdominal e o que explicaria o maior acúmulo lipídico no pulmão direito. $\mathrm{O}$ diagnóstico foi confirmado pelo médico após o paciente mencionar o uso diário do componente lipídico.

Para reforçar a suspeita diagnóstica o paciente teve carcinoma de língua aos 53 anos, realizando cirurgia e tratamento, necessitou de esvaziamento de linfonodos cervicais, na mesma época descobriu metástase do carcinoma na tireoide necessitando de ressecção completa da glândula, após essas intervenções e tratamentos o paciente relatou dificuldade de deglutir, referindo se engasgar e tossir muitas vezes durante as refeições, assim como antes de dormir. 
Realizou fibrobroncoscopia que evidenciou macrófagos com corpos de gordura comprovando a pneumonia lipoídica.

Tabagista desde os 8 anos, em abstinência há 6 meses (54 maços-ano), foi um fator para o médico suspeitar de tumor, pelo padrão encontrado nas imagens, mas foi descartado quando o paciente foi questionado e relatou o uso do óleo mineral, assim como após resultado da fibrobroncoscopia.

História familiar de pai com câncer de reto, falecendo aos 78 anos. $\mathrm{O}$ paciente já realizou colonoscopia há 5 anos e outra há 3 . Pratica atividades físicas há 6 meses assim como cessou o tabagismo nesse mesmo período.

Após o diagnóstico da pneumonia lipoídica, o paciente refere não usar mais óleo mineral, atualmente faz uso diário de lactulose, leite de aveia e tamarine, um laxante fitoterápico, para constipação, persistente, referindo melhora dos sintomas.

Figura 1 - Áreas de consolidação e de atenuação em vidro fosco, associadas a padrão de pavimentação em mosaico no lobo médio e inferior do pulmão direito
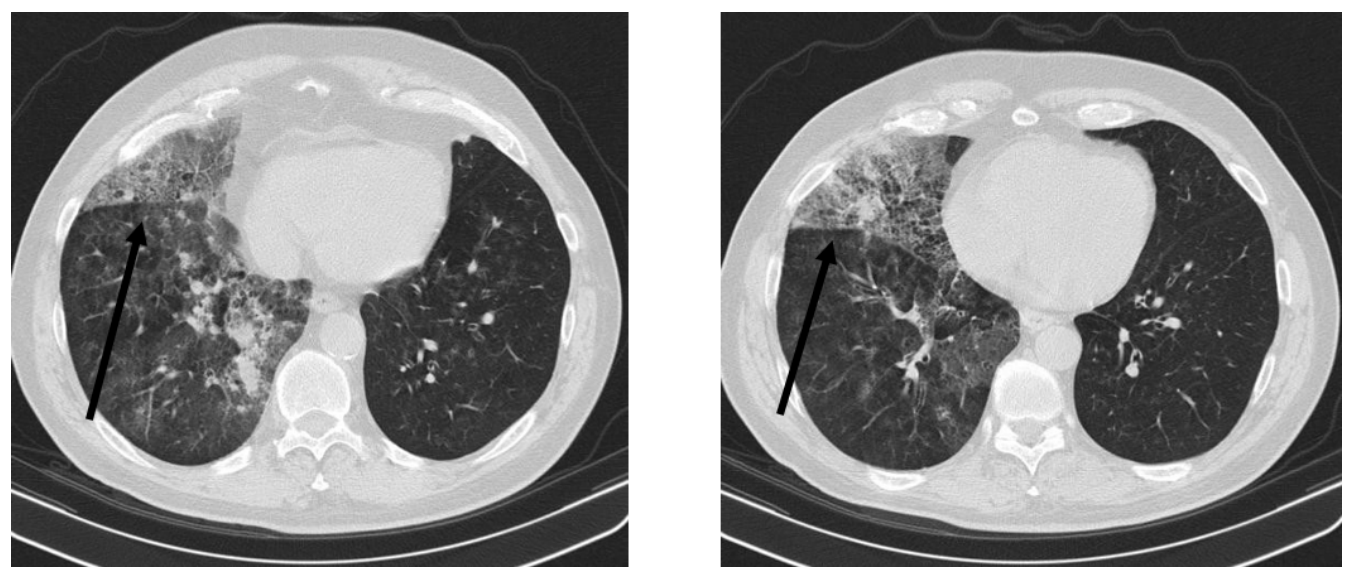

Fonte: Clínica Particular de Estrela (2015).

\section{DISCUSSÃO}

A pneumonia lipoídica é classificada em endógena ou exógena. A endógena resulta de lipídios em degeneração distal a uma obstrução aérea, geralmente se deve a carcinoma pulmonar, podendo também estar associada a condições inflamatórias como abscesso ou bronquiectasias (ADKINS; BENSADOUN, 2004) e a exógena resulta da aspiração ou inalação de partículas oleosas para dentro dos pulmões que pode ou não causar danos dependendo da quantidade e tempo de uso de tais substâncias (LAURENT et al., 1999). 
A pneumonia lipoídica exógena foi inicialmente descrita em 1925 por Laughlen (1925) em quatro pacientes com história prolongada de ingestão de laxante e uso de gotas de nariz à base de óleo (BARON et al., 2003). A incidência exata é desconhecida, muitas vezes só é descoberta na autópsia, e sugere uma incidência aproximada de $1 \%$ e $2,5 \%$, sendo maior nos doentes crônicos e nos idosos (MELTZER et al., 2006).

O material lipídico ingerido ou inalado, estranho ao organismo, não é depurado pelo pulmão e pode acabar inibindo o reflexo da tosse e prejudicando a função normal do epitélio mucociliar, que é manter as vias aéreas limpas, facilitando ainda mais a aspiração dessas substâncias até mesmo em indivíduos sem outras comorbidades associadas (FRANQUET et al., 2000). No caso descrito as comorbidades pré-existentes como o câncer na língua, metástase na tireoide e o esvaziamento linfonodal cervical, favoreceram a exacerbação da microaspiração diária do conteúdo lipídico. Essas substâncias podem não provocar respostas protetoras das vias aéreas (FARIAS et al., 2004), e justamente por não causar irritação ou reflexos, que no caso do paciente já estavam prejudicados por ele ter desenvolvido um distúrbio de deglutição após os tratamentos realizados previamente, houve uma aspiração de maior quantidade aliada ao uso crônico.

Os sintomas não são específicos, variam com o tempo de exposição e com a quantidade aspirada ou inalada. O quadro clínico pode ter uma apresentação parecida com o de pneumonia bacteriana com episódios de febre e tosse assim como dispneia e fraqueza (MARCHIORI et al., 2007).

Muitos pacientes com pneumonia lipoídica exógena são idosos, na sexta ou sétima década de vida, quase metade é assintomática na apresentação, e somente são identificados porque apresentam anormalidades na radiografia de tórax (ADKINS; BENSADOUN, 2004), E, quando apresentam sintomas, eles podem ser confundidos com outras disfunções ou nem sequer ser cogitada uma pneumonia dessa etiologia.

A pneumonia lipoídica exógena consiste em uma reação inflamatória crônica do parênquima pulmonar com envolvimento do interstício devido ao acúmulo de materiais oleosos nos alvéolos (SIAS et al., 2009) ocasionando assim todas as alterações funcionais e as variações que são encontradas nos exames de imagem.

Os exames mostram uma área macroscopicamente mal definida de consolidação ou fibrose parenquimatosa formada pelos macrófagos com material lipídico em seu interior (MULLER et al., 2005), observada principalmente nas partes dependentes do pulmão por exemplo, no lobo médio ou na língula (LEE et al., 1995), evidenciado pela tomografia computadorizada de alta resolução, áreas de consolidação principalmente em pulmão direito (figura 2). 
Figura 2 - Áreas de consolidação em lobo médio e inferior do pulmão direito e pavimentação em mosaico

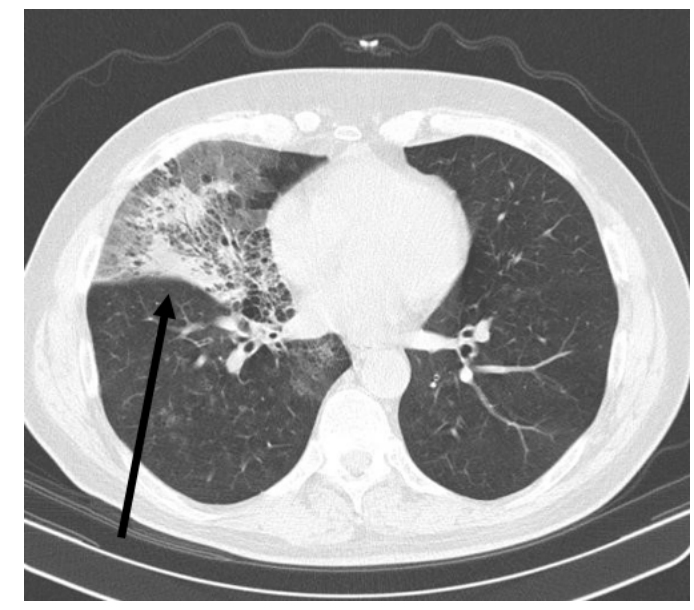

Fonte: Clínica Particular de Estrela (2015).

A Tomografia Computadorizada de Alta Resolução (TCAR) é o melhor exame de imagem para o diagnóstico de pneumonia lipoídica, revelando consolidações alveolares, opacidades em vidro fosco, lesões nodulares e espessamento de septos interlobulares e do interstício intralobular.

A TCAR poderá mostrar extensas opacidades em vidro-fosco ou áreas de consolidação com valores de atenuação entre os de gordura (-90HU- unidades de Housnfield) e os de água (0HU- unidades de Housnfield) (LEE et al., 1995). O diagnóstico pode ser feito pela TCAR justamente por essa apresentação de áreas focais de atenuação de gordura na lesão encontrada no pulmão, que dificilmente será encontrada quando a suspeita for, por exemplo, tumor, ou outro tipo de pneumonia.

O padrão encontrado na TC pode sugerir diversas doenças como proteinose alveolar, pneumonia lipoídica e malignidades bronquioalveolares por isso radiologicamente pode ser difícil fazer um diagnóstico definitivo, necessitando exames adicionais assim como salientando a importância da apresentação clínica e da história colhida do paciente ou da família (ROSSI et al., 2003). Nem sempre será o paciente que irá relatar o uso de substâncias oleosas, será lembrando por um familiar, ou será após indagação direta do médico.

Os diagnósticos diferenciais principais são de consolidação, onde entram as pneumonias bacterianas, os nódulos ou massas como câncer de pulmão ou pneumonia focal,além do "crazy-paving" (pavimentação em mosaico) que engloba proteinose alveolar, adenocarcinoma, pneumonia por Pneumocystis jiroveci ou hemorragia pulmonar (FRANQUET, 2016). 
O tratamento da pneumonia lipoídica se dá primeiramente descontinuando o agente causador e prevenindo exposições futuras. Na ausência de exposição os achados radiológicos tendem a melhorar, ou a se manter inalterados, na maioria das vezes. A terapêutica com corticóides sistêmicos e lavados broncoalveolares tem sido aventada, porém sem benefício definido na literatura (ADKINS; BENSADOUN, 2004).

$\mathrm{O}$ paciente do caso relatado segue sendo acompanhado clínica e radiologicamente, realizou tomografia computadorizada de alta resolução em junho de 2017 a qual evidenciou áreas de consolidação com densidade negativa, de gordura, em lobo médio e inferior do pulmão direito (figura 3), ressaltando o acúmulo de gordura decorrente da aspiração do óleo mineral.

Figura 3 - Áreas de consolidação e de densidade negativa em lobo médio e inferior do pulmão direito.

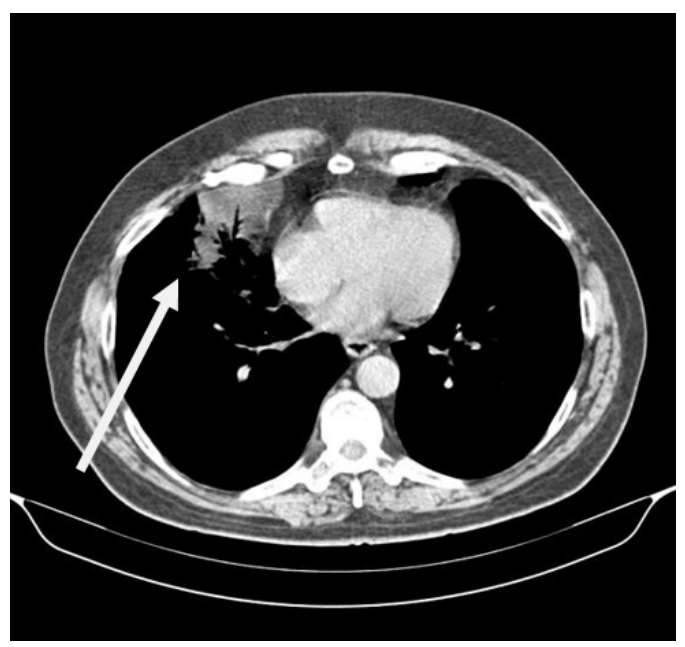

Fonte: Clínica Particular de Estrela (2017).

\section{CONCLUSÃO}

A pneumonia lipoídica é, na maioria das vezes, difícil de diagnosticar por mimetizar várias outras doenças no aspecto clínico e radiológico. O diagnóstico final é baseado na história clínica de uso do óleo mineral, achados radiológicos compatíveis e na presença de lipídios intra-alveolares ou macrófagos carregados de lipídios no lavado bronco alveolar. Atentar para pneumonias refratárias a antimicrobianos e em especial se houver fatores de risco associados. Assim para um manejo e tratamento adequado desses pacientes é necessária uma história clínica completa que possa fornecer dados para a pneumonia dessa etiologia ser suspeitada. 


\section{REFERÊNCIAS}

ADKINS, D.; BENSADOUN, E.S. An 85-year-old man with a lung mass. Chest, v. 125, p.1121-1123, 2004.

BARON, S.E. et al. Radiological and clinical findings in acute and chronic exogenous lipoid pneumonia. J Thorac Imaging, v. 18, p. 217 -224, 2003.

CLÍNICA PARTICULAR DE ESTRELA. Resultados/Diagnósticos. 2015. [Arquivo pessoal].

FARIAS, J. et al. Pneumonia lipídica: Aspectos na tomografia computadorizada: relato de caso. Radiol Bras, v. 37, p. 57-60, 2004.

FRANQUET, T. et al. Aspiration diseases: Findings, pitfalls and differential diagnosis. Radiographics, v. 20, p. 673-685, 2000.

FRANQUET, T. Lipoid Pneumonia. Rio de Janeiro: Elsevier, 2016.

HARO, M. et al. Massive haemoptysis complicating exogenous lipid pneumonia. Eur Respir J., v. 11, p. 507-508, 1998.

LAUGHLEN, G. F. Studies on Pneumonia Following Naso-Pharyngeal Ingections of Oil. Am J Pathol., v. 1, n. 4, p. 407-414, 1925

LAURENT, F. et al. Exogenous lipoid pneumonia: HRCT, MR, and pathologic findings. Eur Radiol, v. 9, n. 6, p. 1190-1196, 1999.

LEE, K.S. et al. Lipoid pneumonia: CT findings. J Comput Assist Tomogr, v. 19, p. 48-51, 1995.

MARCHIORI, E. et al. Pneumonia lipoídica em adultos: aspectos na tomografia computadorizada de alta resolução. Radiol Bras., v. 40, n. 5, p. 315-319, 2007.

MELTZER, E. et al. Lipoid pneumonia: a preventable complication. IMAJ, v. 8, p. 33 $-35,2006$.

MULLER, N.L. et al. Diseases of the lung- radiologic and pathologic correlations. 1. ed. Rio de Janeiro: Revinter, 2005.

ROSSI, S.E. et al. "Crazy-Paving" pattern at thin-section CT of the lungs: Radiologicpathologic overview. RadrioGraphics, v. 23, p. 1509-1519, 2003.

SIAS, S.M. et al. Evolution of exogenous lipoid pneumonia in children: clinical aspects, radiological aspects and the role of bronchoalveolar lavage. J Bras Pneumol., v. 35, n. 9, p. 839-845, 2009. 